\title{
Too much, too young? \\ Altered corticolimbic axonal innervation and resting state functional connectivity suggests sex-dependent outcomes in a rat model of early life adversity
}

\author{
Jennifer A. Honeycuttt ${ }^{1}$, Camila Demaestri ${ }^{1}$, Shayna Peterzell ${ }^{1}$, Marisa M. Silveri ${ }^{2}$, Xuezhu Cai ${ }^{3}$, Praveen Kulkarni ${ }^{3}$, \\ Miles G. Cunningham ${ }^{4}$, Craig F. Ferris ${ }^{3}$, Heather C. Brenhouse ${ }^{1, *}$
}

1 Developmental Neuropsychobiology Laboratory, Dept. of Psychology, Northeastern University. Boston, MA 02115
2 Neurodevelopmental Laboratory on Addictions \& Mental Health, McLean Hospital, Belmont, MA 02478; and
Department of Psychiatry, Harvard Medical School, Boston, MA 02115
${ }^{3}$ Center for Translational Neuroimaging, Dept. of Psychology, Northeastern University, Boston, MA 02115
${ }^{4}$ Laboratory for Neural Reconstruction, Dept. of Psychiatry, McLean Hospital, Belmont, MA 02478
${ }^{*}$ Correspondence: H.Brenhouse@NEU.edu; 360 Huntington Ave NI125, Northeastern University, Boston, MA 02115

\begin{abstract}
Adverse early experiences significantly alter behavioral and neural trajectories via aberrant brain maturation. Children with a history of early life stress (ELS) exhibit maladaptive behaviors and increased risk of mental illness later in life. Evidence in ELSexposed humans identifies a role of atypical corticolimbic development; specifically, within amygdala-prefrontal cortex (PFC) circuits, and show precocially mature task-based corticolimbic functional connectivity (FC). However, the neurobiological substrates of such ELS-driven developmental changes remain unknown. Here, we identify putative neurobiological changes to determine the timeline of developmental perturbations following ELS in rats. Anterograde axonal tracing from basolateral amygdala (BLA) to pre- and infralimbic (PL, IL) PFC was quantified at postnatal days (PD)28, 38, and 48, along with anxiety-like behavior, in maternally separated (ELS) or control reared (CON) male and female rats. Resting state ( $r s$ )FC was assessed at PD28 and PD48 in a separate cohort. We report that ELS-exposed female rats show early maturation of BLA-PFC innervation at PD28, with ELS-related changes in males not appearing until PD38. ELS disrupted the maturation of rsFC from PD28 to PD48 in females, with enduring relationships between early rSFC and later anxiety-like behavior. Only transient ELS-related changes in rsFC were seen in male PL. Together, these data provide evidence that female rats may be more vulnerable to the effects of ELS via precocial BLA-PFC innervation, which may drive altered corticolimbic rsFC. These data also provide evidence that increased BLA-IL rSFC is associated with behavioral resiliency following ELS in female rats, providing mechanistic insight into the underlying etiology of adversity-induced vulnerability and resiliency.
\end{abstract}

Keywords: Maternal Separation, Early Life Adversity, Prefrontal Cortex, Basolateral Amygdala, Development, Anxiety

\section{Introduction}

Exposure to early life stress (ELS) leads to increased vulnerability to various psychiatric disorders across the lifespan (Callaghan and Tottenham, 2016; Hane and Fox, 2016; Krugers et al., 2017; Maccari et al., 2014; McEwan, 2008; Smyke et al., 2007). Males and females appear to be affected differently by ELS, with females more prone to developing disorders including anxiety and depression (Davis and Pfaff, 2014; Hammen et al., 2000; Heim et al., 2008). Importantly, these sequelae often emerge later in childhood or adolescence, providing an opportunistic window for intervention before psychopathology takes hold. Thus, development of effective intervention strategies requires biological and developmental targets specific to individuals based on factors including sex and timing of stress exposure (Lupien et al., 2009). Growing evidence suggests that ELS in humans leads to life-long changes in connectivity and/or functionality of limbic and cortical regions (Choi et al., 2009; Van Tieghem and Tottenham, 2018), with consequential deficits in emotion regulation and cognition (Tyrka et al., 2013). Human and animal studies highlight the importance of corticolimbic circuitry in affective behavior regulation, its disruption in mental disorders (Bangasser and Valentino, 2014; Herringa et al., 2013; Killgore et al., 2014), and alterations directly related to ELS (Kaiser et al., 2018). Specifically, Tottenham and colleagues illustrated that normative developmental changes in task-based functional connectivity (FC) between amygdala and medial prefrontal cortex (mPFC) are accelerated after ELS with associated changes in anxiety (Gee et al., 2013a) and are particularly evident in females (Dickie and Armony, 2008). Indeed, children institutionalized during the first two years of life in orphanages display precocial development of amygdala-mPFC FC, though the anatomical substrates for this accelerated connectivity remain unknown.

In rats, the basolateral amygdala (BLA) sends inputs to the MPFC and modulates anxiety-related behaviors (Felix-Ortiz et al., 2016), recall of emotionally salient information (McGaugh, 2004), decision-making (St. Onge et al., 2012), and goal-directed behavior (Schoenbaum et al., 2000). Notably, two subpopulations of BLA neurons project to different regions of the mPFC (Senn et al., 2014): projections to the dorsal (prelimbic; PL) region of the $\mathrm{MPFC}$ are active during threat-associated fear learning and expression, whereas projections from the BLA to the ventral (infralimbic; $\mathrm{IL})$ region of the $\mathrm{MPFC}$ are active upon extinction of fear, or learning about safety signals. In typically developing male rats, BLA innervation of mPFC increases through adolescence (Cunningham et al., 2002), likely contributing to healthy maturation of threat and safety appraisal. Interestingly, BLA-mPFC axonal innervation has not yet been evaluated in females, nor has any study examined the effects of ELS on BLA-derived innervation of PL or IL. 
bioRxiv preprint doi: https://doi.org/10.1101/700666; this version posted October 7, 2019. The copyright holder for this preprint (which was not certified by peer review) is the author/funder, who has granted bioRxiv a license to display the preprint in perpetuity. It is made available under aCC-BY-NC-ND 4.0 International license.

Honeycutt et al., 06 OCT 2019 - preprint copy - BioRxiv

Little is known about the interaction of sex and ELS on corticolimbic development (Herringa et al., 2013), despite striking sex differences in clinical time-course and symptomology of ELS effects (Martin et al., 2014; Wainwright and Surtees, 2002). Notably, typically developing females display earlier maturation of the PFC (Lenroot et al., 2007; Lenroot and Giedd, 2010). Identifying how ELS affects these sex-dependent trajectories is crucial to understanding sex differences in vulnerability and to develop individually targeted intervention strategies. Therefore, we used anterograde tracing to examine ELS effects on BLA-PFC innervation over development in male and female rats. We hypothesized that if heightened anxiety-like behaviors following ELS are associated with increased BLA-derived PFC innervation, then rats exposed to ELS via repeated maternal and peer separation will display anxiety-like behavior and increased BLA-PFC innervation that will be more robust in females.

While task-based FC illustrates coordinated responsivity to anxietyprovoking stimuli (Gee et al., 2013a), resting-state FC (rsFC) is excellent for probing the functional integrity of the amygdala-PFC circuit independent of task demands (Alarcón et al., 2015; Gabard-Durnam et al., 2016; Thomason et al., 2011a; 2011b). ELS effects on corticolimbic rsFC in humans are inconsistent, likely because of reliance on autobiographical questionnaires, different ages of measurement, and different ELS criteria. In rats, maternal separation results in early emergence of both adult-like fear learning based in fronto-amygdala circuitry (Callaghan and Richardson, 2011) and early amygdala structural maturation (Ono et al., 2008). Early maturation of corticolimbic connectivity likely has deleterious consequences because a sufficient degree of PFC immaturity during juvenility is critical for learning anxiolytic cues (safety signals) in adulthood (Yang et al., 2012). Therefore, we provide a back-translation to examine whether ELS-exposed rats display accelerated maturation of amygdala-PFC connectivity to parallel humans with a history of adversity, with increased BLA-PFC innervation as an anatomical substrate driving sex-specific developmental effects.

\section{Methods and Materials}

\section{Subjects}

For Studies 1 (BLA-mPFC innervation) and 2 (rsFC), timed-pregnant Sprague-Dawley rats (Charles River, Wilmington, MA) arrived at gestational day 15 . Rats were housed under standard laboratory conditions in a $12 \mathrm{~h}$ light/dark cycle (lights on at 0700h) temperature- and humidity-controlled vivarium with access to food and water ad libitum. Following birth (postnatal day [PD]0), litters were randomly assigned as either: control (CON), and left undisturbed with the exception of cagechanging twice/week and weighing (PD9, 11, 15, 20); or ELS via maternal and peer separation, as described previously (Coley et al., 2019; Farrell et al., 2016; Ganguly et al., 2019; Grassi-Oliveira et al., 2016; Wieck et al., 2013) and below. On PD1 litters were culled to 10 (+/-2) pups, maintaining equal ratio of male and female whenever possible, with one rat per litter assigned to each experimental group (i.e. age and sex) to avoid litter effects.

ELS pups were separated from dams and littermates in individual cups with home cage pine shavings in a circulating water bath (37oC) from PD2-PD10. At PD11-20, when body temperature is self-regulated, pups were individually separated into cages. Pups were separated for 4 hours each day (0900h-1300h) during which time pups were deprived of maternal and litter tactile stimulation and nursing, but not from maternal odor. ELS dams remained in their home cages but were deprived of their entire litters during separations. Pups were weaned at PD21 into samesex mixed-litter pairs and left undisturbed until surgery/behavioral assessment for Study 1 (either PD21/28, 31/38, or 41/48; Fig1A). Separate cohorts were used for Study 2 - with treatment identical to Study 1 - and left undisturbed until behavioral assessment and rsFC
(PD28, PD48), with subjects imaged at both ages. Experiments were performed in accordance with the 1996 Guide for the Care and Use of Laboratory Animals (NIH) and with approval from Northeastern University's Institutional Animal Care and Use Committee.

\section{Study 1: BLA-PFC Innervation \\ Surgeries}

Male and female rats from CON and ELS litters at PD21, PD31, or PD41 underwent stereotaxic injections of biotinylated dextran amine (BDA; Life Technologies NeuroTrace 10,000MW Anterograde Tracer Kit; reconstituted to $10 \%$ with phosphate buffered saline (PBS)) into BLA (Fig1B). For maximal uptake without excess bolus, 200nL (0.2 $\mu \mathrm{l})$ of BDA was injected into the BLA using a mounted 32-gauge Neuros syringe (Hamilton Company) attached to a microinfusion pump (11 Elite Nanomite; Harvard Apparatus).

Rats were first anesthetized with Isoflurane in an induction chamber before beginning surgical procedures. Surgical site was shaved, and the animal was secured via ear bars with top incisors positioned over a bite bar within a nose cone to provide continuous Isoflurane anesthetic during surgery. A subcutaneous injection of buprenorphine $(0.03 \mathrm{mg} / \mathrm{kg}$ body weight) was administered as a postoperative analgesic. Once sufficiently anesthetized, measured via lack of pedal reflex, a skin incision was made along the midline of the skull to visualize Bregma and Lambda. Dorsal-ventral (DV) coordinates for Bregma and Lambda were taken to ensure that the skull was level, and Bregma was used as a landmark to navigate to the position above the BLA, where a small hole was drilled into the right hemisphere of the skull, and the needle was slowly lowered into the BLA (Fig1B). DV depth was calculated from dura surface to account for individual differences in skull thickness. Once needle was lowered to the target, BDA was slowly infused at a rate of $40 \mathrm{~nL} / \mathrm{min}$ over the course of 5 minutes and left in place for an additional 5 minutes to allow for diffusion of BDA solution before being slowly retracted. The incision was sutured, and rats were returned to individual cages and allowed

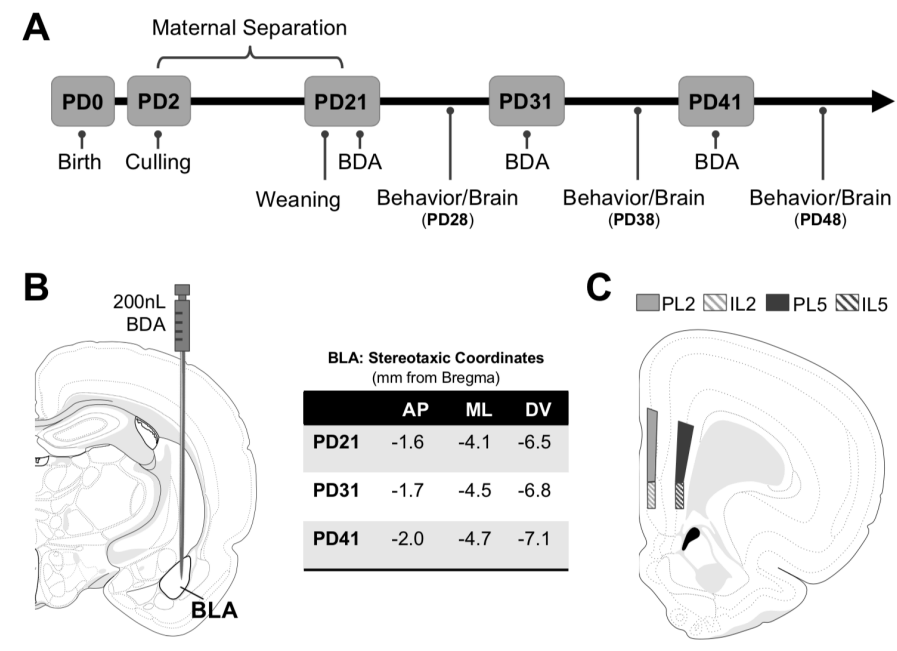

Figure 1. Timeline and methodology for study 1.

(A) Methodological timeline for Study 1 indicating maternal separation (for ELS groups), weaning timeline, and surgical/behavioral milestones. Biotinylated Dextran Amine (BDA) microinfusions were performed at PD21, PD31, or PD41. Behavior (elevated plus maze; EPM) was performed at PD28, PD38, or PD48, and was followed by brain collection. (B) Stereotaxic coordinates for surgeries at each developmental time point and anatomical map of basolateral amygdala (BLA) injection site where 200nL of BDA was infused via Hamilton Neuros syringe. (C) Neuroanatomical map of quantified regions of BLA-PFC axonal innervation. Quantification was conducted via unbiased stereology within the prelimbic (PL) and infralimbic (IL) in layers 2 and 5. Atlas modified from Swanson (2018).

AP (anterior-posterior); ML (medial-lateral); DV (dorsal-ventral) 
bioRxiv preprint doi: https://doi.org/10.1101/700666; this version posted October 7, 2019. The copyright holder for this preprint (which was not certified by peer review) is the author/funder, who has granted bioRxiv a license to display the preprint in perpetuity. It is made available under aCC-BY-NC-ND 4.0 International license.

Honeycutt et al., 06 OCT 2019 - preprint copy - BioRxiv

6 days for recovery before behavioral testing, with all brain tissue collected one-week post-surgery.

\section{Behavioral Assessment: Elevated Plus Maze}

Elevated Plus Maze (EPM) performance was evaluated 6-7 days postsurgery in all animals. The apparatus was constructed of opaque Plexiglas with four radiating arms $(50 \mathrm{~cm} \times 10 \mathrm{~cm})$ around a center square $(10 \mathrm{~cm} \times$ $10 \mathrm{~cm}$ ), with $40 \mathrm{~cm}$-high walls surrounding two opposing arms, leaving the other two arms open. Between each animal $50 \%$ ethanol solution was used to clean the apparatus. Rats were acclimated to the testing room for $10 \mathrm{~min}$ before testing began and were then placed in the center square of the apparatus under red light facing a closed arm. Behavior was recorded for 5 minutes by an observer blind to condition. Behavioral scoring included: four-paw entries into/time spent (seconds) in open and closed arms, number of arm crossings, and head dips.

\section{Tissue Collection and Inclusion Criteria}

7 days post-surgery, rats were deeply anesthetized with $\mathrm{CO} 2$ and transcardially perfused with ice-cold $(0.9 \%)$ saline, followed by ice-cold $4 \%$ paraformaldehyde solution. Brains were extracted and stored in $4 \%$ paraformaldehyde solution for 1 week before being transferred to a $30 \%$ sucrose solution for 4 days for cryoprotection. All brains were sliced into $40 \mu \mathrm{m}$ serial sections on a freezing microtome (Leica), with serial sections placed in well plates filled with freezing solution for $-20 \mathrm{C}$ storage. Sections taken for analysis included: PFC $(+5.2 \mathrm{~mm}$ through $+2.5 \mathrm{~mm}$ from Bregma) and BLA (-1.4mm through $-3.6 \mathrm{~mm}$ from Bregma) as outlined in Paxinos and Watson (1997). Serial sections were collected such that coronal sections within a single well were separated by approximately $240 \mu \mathrm{m}$.

BLA-derived axonal innervation of the PFC, and BLA injection bolus for each animal, was visualized using diaminobenzidine (DAB) as indicated by the manufacturer (NeuroTrace BDA Kit, Life Technologies). One well for each animal was used for each brain region (PFC, BLA). Free-floating sections were washed $2 \times 10 \mathrm{~min}$ in PBS $(7.4 \mathrm{pH})$ on an agitator before being transferred into Avidin solution (1:4000 in 0.3\% PBS-T; Life Technologies NeuroTrace BDA Kit) overnight at $40 \mathrm{C}$ on an agitator. Sections were then washed $3 \times 5 \mathrm{~min}$ in PBS and transferred into $0.05 \%$ DAB solution (Life Technologies NeuroTrace BDA kit) for 10 minutes for processing. Stained sections were washed in PBS, mounted on glass slides and coverslipped with DPX. Adjacent sections were randomly sampled from each experimental group ( $n^{\prime} s=4 /$ group) and stained with Cresyl Violet to determine average volume of the BLA based on age, sex, and condition. There were no significant differences based on sex or condition, thus volumes were collapsed across these to determine the average BLA volume per age (Supplemental Fig1).

A

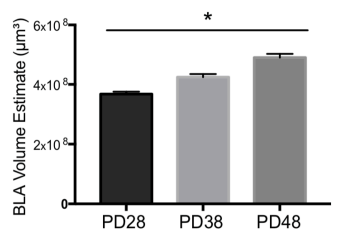

C

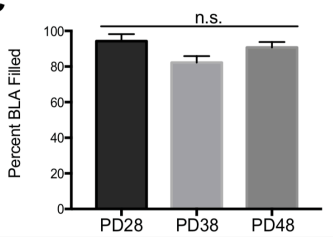

B

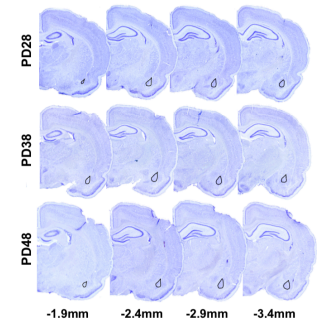

D

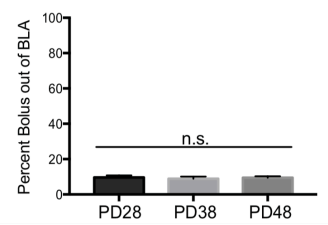

$\mathrm{E}$

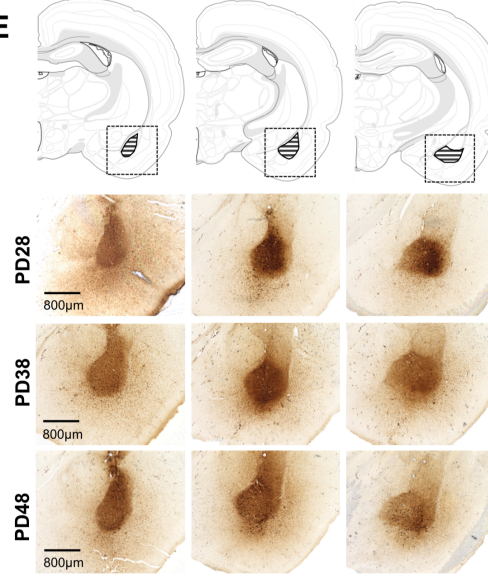

Figure 2. BLA volume and BDA anterograde tracer bolus sites. The average volume of the BLA significantly increased with age (A) as quantified via Cresyl Violet staining of adjacent tissue sections (B). As there were no significant differences as a function of sex or rearing condition on BLA volume estimates at each age group, data were collapsed for each age with a final number of $n=16$ per age group. Anatomical coordinates located below Nissl-stained sections (B) indicate the approximate distance (in $\mathrm{mm}$ ) from Bregma. There were no significant differences in the percent of BLA filled by the BDA anterograde tracer bolus between ages (C), nor was there any significant difference in the amount of bolus located outside of the BLA structure (D). $n=6-9$ per group (C; D) before collapsing within each age due to a lack of differences as a function of sex or rearing condition at each age (therefore, the number of data points per age group for analyses in $\mathbf{C}$ and $\mathbf{D}$ were 24-36). Panel (E) shows representative photomicrographs of BDA bolus across the extent of the BLA for each age examined. Atlas modified from Swanson (2018).

${ }^{*} p<0.05 ;$ n.s. (non-significant) 
bioRxiv preprint doi: https://doi.org/10.1101/700666; this version posted October 7, 2019. The copyright holder for this preprint (which was not certified by peer review) is the author/funder, who has granted bioRxiv a license to display the preprint in perpetuity. It is made available under aCC-BY-NC-ND 4.0 International license.

Honeycutt et al., 06 OCT 2019 - preprint copy - BioRxiv

included in statistical analyses of EPM. However, all correlational analyses including behavioral data were performed only with the data from cases meeting neuroanatomical inclusion criteria. All statistical analyses were performed in either SPSS V25 (IBM) or PRISM 8 (Graphpad).

\section{Study 2: Resting State Functional Connectivity (rsFC)}

MRI scanning was performed on male and female CON and ELS subjects at PD28 and PD48 in a Bruker BioSpec 7.0T/20cm USR horizontal magnet (Bruker, Billerica, MA) with a $20-\mathrm{G} / \mathrm{cm}$ magnetic field gradient insert $(I D=12 \mathrm{~cm})$ capable of $120 \mu$ s rise time. Rats were anesthetized and maintained at $1-2 \%$ isoflurane and oxygen with a flow rate of $1 \mathrm{~L} / \mathrm{min}$ throughout scanning, with breathing rate (40-50 breaths per minute) carefully monitored by an investigator and anesthetic levels adjusted accordingly. Rats were scanned at $300 \mathrm{MHz}$ using a quadrature transmit/receive volume coil built into the rat head holder and restraint system (Animal Imaging Research, Holden, MA). rsFC was acquired by gradient-echo triple-shot echo-planar imaging (EPI) pulse sequence with the following parameters: matrix size $=96 \times 96 \times 20$; repetition time $(T R) /$ echo time $(T E)=3000 / 15 \mathrm{msec}$; voxel size $=0.312 \times 0.312 \times 1.2 \mathrm{~mm}$; slice thickness $=1 \mathrm{~mm}$; volume $=200$. T2-weighted high-resolution anatomical scans were conducted using RARE pulse sequence with imaging parameters as follows: matrix size $=256 \times 256 \times 20 ; \mathrm{TR} / \mathrm{TE}=$ $4369 / 12 \mathrm{msec}$; voxel size $=0.117 \times 0.117 \times 1 \mathrm{~mm}$; slice thickness $=1 \mathrm{~mm}$.

\section{Pre-Scan Elevated Plus Maze}

Prior to both PD28 and PD48 imaging, subjects were evaluated for anxiety-like behavior in the EPM to determine whether it could be predictive of rsFC alterations, and whether juvenile behavior/rsFC might be predictive of later adolescent outcomes in the same rat. Methods identical to Study 1.

\section{Analysis of rsFC and Behavior}

rsFC was measured using seed-based voxel-wise analysis, with BLA as the seeded region. rSFC between BLA and $I L$ and $P L$ regions of PFC were the focus of the present study. Data analyses were conducted using Analysis of Functional Neurolmages (AFNI_17.1.12; NIH), FMRIB software library (FSL, v5.0.9), and Advanced Normalization Tools (http://stnava.github.io/ANTs/). Resting-state Blood Oxygen-Level Dependent (BOLD) data were used for brain-tissue data extraction using 3Dslicer (https://www.slicer.org). Skull-stripped data were despiked to remove large signal fluctuations due to scanner and physiological artifacts. Slice-timing correction was conducted to correct data from interleaved slice order acquisition. Head motion correction was carried out using six parameters, with first volume as reference slice. Each subject was registered to a standard MRI Rat Brain Template (Ekam Solutions LLC, Boston, MA) using non-linear registration. In order to further reduce motion effects and physiological fluctuations, regressors comprised of six motion parameters, the average BOLD signal in white matter and ventricular regions, as well as motion outliers among all data volumes were fed into a nuisance regression model. Band-pass temporal filtering $(0.01 \mathrm{~Hz}-0.1 \mathrm{~Hz})$ and spatial smoothing $(\mathrm{FWHM}=0.6 \mathrm{~mm})$ were performed on the residual data followed by signal detrending.

Whole brain voxel-wise Pearson's correlation coefficients were calculated for each subject and were transformed for normality using Fisher's z. Because this experiment was conceived to follow up on observed sex-specific effects on innervation measures, a priori hypotheses drove the use of a two-way mixed ANOVA within each sex (age as a within-subjects factor and stress as a between-subjects factor) in lieu of a three-way ANOVA. Therefore, two-way ANOVAs were conducted for each sex using AFNI 3dLME, with a false discovery rate curve computed. Post-hoc contrast effects focusing rearing condition
(CON vs. ELS) at two levels of age (PD28 or PD48), as well as contrasts effects of age at two levels of rearing condition, were conducted where appropriate. Findings with a voxel-wise uncorrected $p<0.005$, with a minimum cluster size of 30 voxels, was regarded as statistically significant.

Linear regressions were conducted to determine the relationship between EPM performance and correlation coefficients of BLA-seeded rsFC data for PL and IL in male and female rats. Since rats were tested at two time points, regressions were also performed to assess whether juvenile outcomes (behavior and/or rsFC) were predictive of later adolescent outcomes. Fisher's $r$ - to- $z$ transformations were performed to determine any significant impact of sex or rearing on the strength of the relationships. All statistical analyses for behavior, as well as regression analyses to determine relationships between rSFC correlation coefficients and behavior, were performed in either SPSS V25 (IBM) or PRISM 8 (Graphpad).

\section{$\underline{\text { Results }}$}

\section{Study 1: Neuroanatomy and Axonal Innervation} BLA volume:

A subset of tissue from each group was analyzed for BLA volume with Cresyl Violet. Average BLA volume for each age (PD28, PD38, PD48) was calculated using the Cavalieri probe in Stereolnvestigator ( $n=16$ per age). Two-way ANOVA for each age revealed no effects of sex or rearing on BLA volume (Supplemental Fig1). Thus, results were pooled across sex and rearing to determine BLA volume across development. One-way ANOVA showed a main effect of age $\left(F_{2,48}=31.74, p<0.0001\right)$. Comparisons revealed increased BLA volume between PD28 and PD38 ( $p$ $=0.002)$, PD28 and PD48 $(p<0.0001)$; and PD38 and PD48 $(p=0.0002)$ (Fig2A).

\section{BLA Bolus:}

Standard deviation of BLA volumes within each age deviated $~ 1 \%$ from mean volume, therefore percent BDA-filled BLA was calculated by dividing bolus volume in BLA in each animal by average BLA volume per age. Percent bolus outside BLA was calculated for each animal by dividing total bolus outside of BLA by total bolus volume.

Since age differences were detected in BLA volume, we examined whether amount of BLA filled differed with age. One-way ANOVA revealed no effect of percent BLA filled $\left(F_{2,88}=3.030, p=0.053\right.$; small effect size: partial $\eta 2=0.06$ ) (Fig2C), and no effect of percent bolus outside of BLA across age $\left(F_{2,88}=0.133, p=0.876\right)($ Fig2D,E).

To ensure that percentage of bolus within BLA did not drive individual differences in PFC axonal innervation, linear regressions were used to determine correlations between percent of filled BLA volume and total innervation in the PFC, as well as the percent of BLA filled with tracer and total innervation in the PFC. These revealed no relationship between percent BLA filled and total innervation at any age (PD28: $R^{2}(28)=0.064$, $p=0.178 ;$ PD38: $R^{2}(27)=0.004, p=0.738 ;$ PD48: $R^{2}(30)=0.057, p=$ $0.189)$. Additionally, linear regression analyses were used to investigate possible relationships between the total bolus volume (both within and outside of the BLA) and total PFC innervation, which revealed no significant correlation at any age (PD28: $R^{2}(28)=0.062, p=0.185$; PD38: $R^{2}(27)=0.006, p=0.696$; PD48: $R^{2}(30)=0.090, p=0.096$ ) (Supplemental Fig2).

\section{BLA-Derived Axonal Innervation:}

There were no differences in probe volume or mounted thickness ( $p$ $>0.1$ ) between groups based on age, sex, or rearing; thus, all analyses are presented as collected without corrections (Supplemental Fig3). 
bioRxiv preprint doi: https://doi.org/10.1101/700666; this version posted October 7,2019 . The copyright holder for this preprint (which was not certified by peer review) is the author/funder, who has granted bioRxiv a license to display the preprint in perpetuity. It is made available under aCC-BY-NC-ND 4.0 International license.

Honeycutt et al., 06 OCT 2019 - preprint copy - BioRxiv
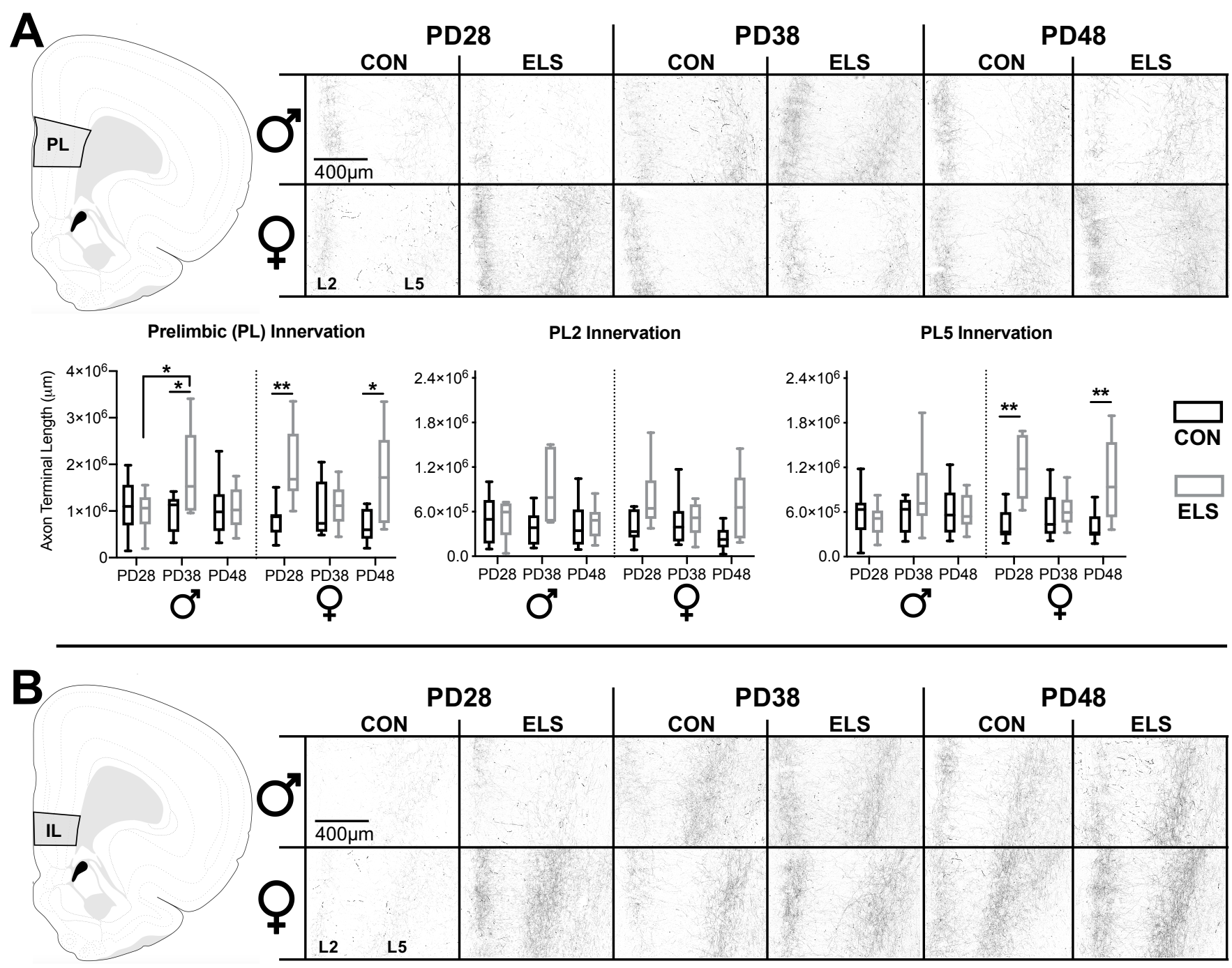

Infralimbic (IL) Innervation

IL2 Innervation

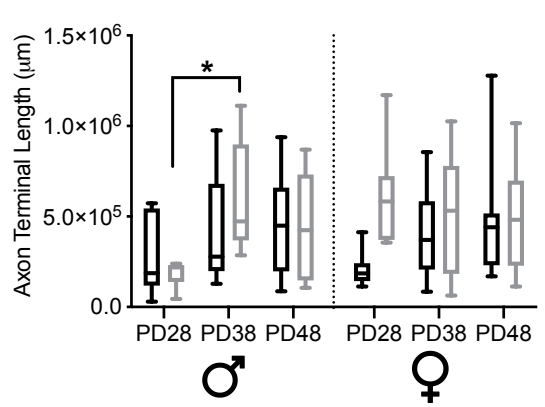

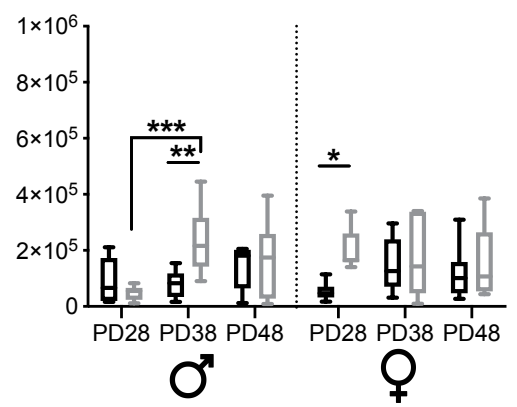

IL5 Innervation

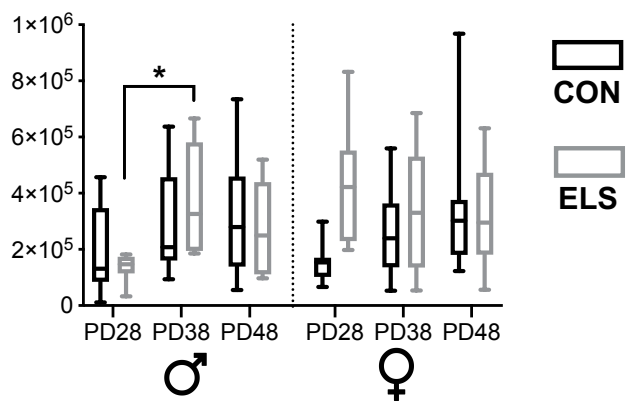

Figure 3. ELS leads to precocial BLA-PFC axonal innervation earlier in female than in male rats.

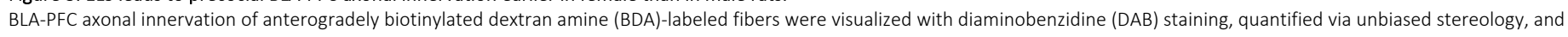

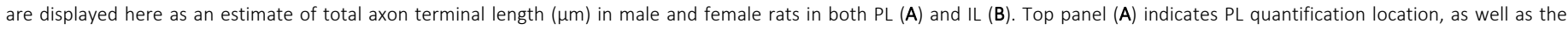

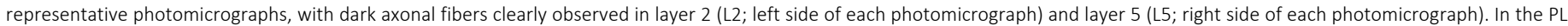

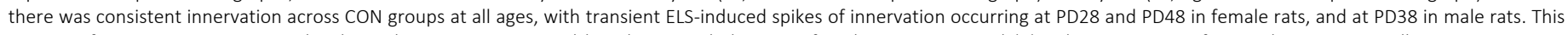

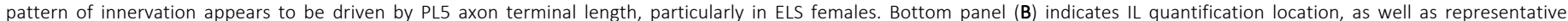

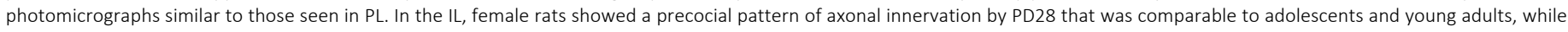

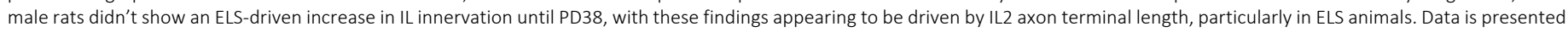

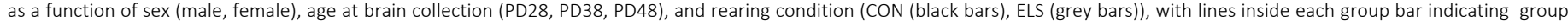

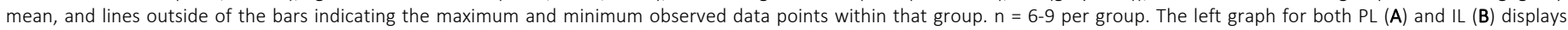

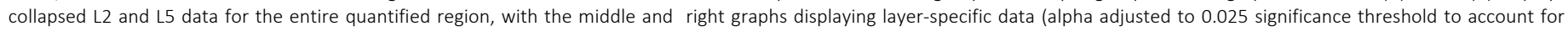
multiple comparisons in subsequent two-way ANOVAs). Photomicrographs were imaged at 10x mag. Atlas modified from Swanson (2018).

${ }^{*} p<0.05$ (for IL/PL Innervation graphs); ${ }^{*} p<0.025$ (for individual L2 and L5 innervation graphs); $* * p<0.01 ;{ }^{* * *} p<0.001$ 
bioRxiv preprint doi: https://doi.org/10.1101/700666; this version posted October 7, 2019. The copyright holder for this preprint (which was not certified by peer review) is the author/funder, who has granted bioRxiv a license to display the preprint in perpetuity. It is made available under aCC-BY-NC-ND 4.0 International license.

Honeycutt et al., 06 OCT 2019 - preprint copy - BioRxiv

\section{PL innervation:}

A three-way ANOVA to determine effects of rearing, sex, and age on BLA-PL innervation revealed a main effect of rearing $\left(F_{1,79}=14.294, p<0.0001\right)$, and a three-way interaction $\left(F^{2}, 79=5.244, p=\right.$ 0.007). Two-way ANOVA of male PL innervation showed a trending age $x$ rearing interaction $\left(F_{2,42}=2.748, p=\right.$ 0.076 ) with a moderate effect size (partial $\eta 2=0.116$ ); follow-up post-hoc showed an ELS-driven increase in innervation at PD38 compared to $\operatorname{CON}(p=0.031)$. Increased innervation at PD38 compared to PD28 was observed in ELS ( $p=0.044)$. Twoway ANOVA of female PL innervation showed a main effect of rearing $\left(F_{1,38}=\right.$ 14.21, $p<0.001)$, with post-hoc indicating more PL innervation in ELS compared to CON at PD28 ( $p=0.009)$ and PD48 ( $p=0.010)$. Graphs detailing comparisons, as well as representative photomicrographs of $\mathrm{PL}$, can be seen in in Fig3A.

Three-way ANOVAs to delineate layer-specific effects in $\mathrm{PL}$ revealed a main effect of rearing in PL2 $\left(F_{1,79}=12.511, p=0.001\right)$ and PL5 $\left(F_{1,79}=\right.$ $12.925, p=0.001)$. There were significant rearing $\times$ sex $\times$ age interactions in $\mathrm{PL2}\left(F_{2,79}=4.655, p=0.012\right)$ and PL5 $\left(F_{2,79}=4.699, p=0.012\right)$. In PL5, a rearing $x$ sex interaction was observed $\left(F_{1,79}=7.775, p=0.007\right)$. Twoway ANOVAs were conducted for each sex. In PL2, males failed to show age ( $p=0.202)$ or rearing ( $p=0.043$ ) effects that met the Bonferronicorrected a of 0.025. However, two-way ANOVA in females revealed a main effect of rearing $\left(F_{1,46}=5.344, p=0.025\right)$ in PL2. Within PL5, males showed no significant effects or interactions $(p>0.10)$. However, twoway ANOVAs of PL5 innervation in females revealed a main effect of rearing $\left(F_{1,38}=17.760, p=0.0001\right)$. Post-hoc revealed an effect of rearing with female ELS showing more PL5 innervation than CON at P28 ( $p=$ $0.002)$ and $\mathrm{P} 48(p=0.007)$.

\section{IL Innervation:}

Three-way ANOVA revealed no overall main effects or interactions in the IL as a whole, however a trending main effect of rearing was noted $(p \geq 0.07)$. However, since our a priori hypothesis was that the effects of ELS would be sex specific, we also performed separate 2-way ANOVAs for males and females. Two-way ANOVA in males showed a main effect of age $\left(F_{2,40}=4.355, p=0.019\right)$, with increased IL innervation from PD28 to PD38 $(p=0.015)$ in ELS. Two-way ANOVA in females showed no main effect of age nor an age $x$ rearing interaction. Graphs detailing comparisons, as well as representative photomicrographs of IL, can be seen in in Fig3B.

Three-way ANOVAs were conducted for IL2 and IL5. Adjusted a was set to 0.025 to correct for multiple comparisons. In IL2, a main effect of rearing was evident $\left(F_{1,79}=5.938, p=0.017\right)$, with no main effects or interactions in IL5 $(p>0.10)$. Two-way ANOVAs were conducted for each sex and sub-region. Males displayed a main effect of age $\left(F_{2,39}=4.411, p\right.$ $=0.019)$ in IL2, and a rearing $x$ age interaction $\left(F_{2,39}=4.521, p=0.017\right)$. Male ELS showed more IL2 innervation compared to CON at PD38 ( $p=$ $0.007)$. Developmentally, male ELS had more innervation at PD38 than PD28 $(p<0.001)$. In females, there was a trending main effect of rearing $\left(F_{1,38}=4.791, p=0.035\right)$ with a moderate effect size (partial $\left.\eta 2=0.126\right)$, with more IL2 innervation in ELS than CON at PD28 ( $p=0.037)$. Two-way ANOVA on male IL5 showed a trending main effect of age $\left(F_{2,40}=3.541\right.$, $p=0.038$; partial $\eta 2=0.178)$, with post-hoc revealing more innervation at PD38 than PD28 in ELS $(p=0.048)$. Two-way ANOVA on female IL5 showed no main effects $(p>0.1)$ or interaction $(p=0.096)$.
B

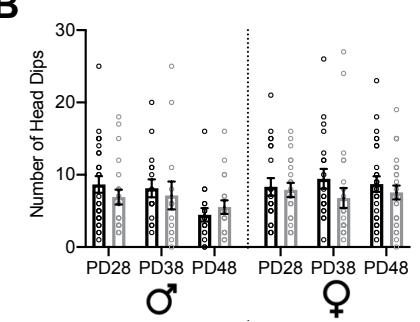

C

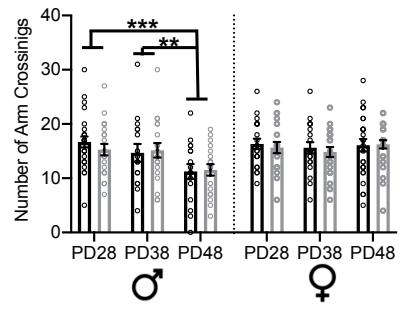

\section{EPM:}

Three-way ANOVA comparing time spent in the open arms showed an interaction of age $x$ rearing $\left(F_{2,224}=3.06 ; p=0.049\right)$ and of sex $x$ rearing $\left(F_{2,224}=5.98 ; p=0.015\right)$ (Fig4A). Two-way ANOVAs revealed a main effect in females of rearing $\left(F_{1,128}=12.69, p=0.0005\right)$, with ELS females spending less time in the open arms than CON at PD38 $(p=0.0176)$. No effects of treatment or age were observed in males $(p>0.40)$. Arm crossings and head dips were also analyzed. No interactions or main effects of age, sex, or rearing were found with a 3-way ANOVA on head dips (Fig4B), however an age $x$ sex interaction $\left(F_{2,242}=6.73 ; p=0.001\right)$ and follow-up 2-way ANOVA revealed a main effect of age in males (main effect of age: $\left.F_{2,114}=7.22 ; p=0.007\right)$, with fewer arm crosses at PD48 than at PD28 ( $p=0.0006)$ or PD38 $(p=0.0203)$ (Fig4C).

\section{Relationships Between Innervation and Behavior}

Results from all analysis of correlation between behavior on the EPM and connectivity measures are shown in Table 1 . Here we discuss significant correlations, which are illustrated in Fig5A-D. Fisher's r- to- z transformations revealed an impact of sex, but not rearing, on the

\begin{tabular}{|c|c|c|c|c|}
\hline \multirow{3}{*}{ PD28 } & \multicolumn{2}{|c|}{$\begin{array}{c}\text { PL Innervation vs. } \\
\text { Time in Open }\end{array}$} & \multicolumn{2}{|c|}{$\begin{array}{l}\text { IL Innervation vs. } \\
\text { Time in Open }\end{array}$} \\
\hline & $\begin{array}{l}\text { MALE } \\
\mathrm{n}=16\end{array}$ & $\begin{array}{c}R=0.209 ; R^{2}=0.044 \\
p=0.437\end{array}$ & $\begin{array}{l}\text { MALE } \\
\mathrm{n}=14\end{array}$ & $\begin{array}{c}R=0.158 ; R^{2}=0.025 \\
p=0.560\end{array}$ \\
\hline & $\begin{array}{l}\text { FEMALE } \\
\mathrm{n}=14\end{array}$ & $\begin{array}{c}R=0.188 ; R^{2}=0.035 \\
p=0.519\end{array}$ & $\begin{array}{l}\text { FEMALE } \\
\mathrm{n}=12\end{array}$ & $\begin{array}{c}R=0.691 ; R^{2}=0.478 \\
p=0.009^{\star *}\end{array}$ \\
\hline \multirow{2}{*}{ PD38 } & $\begin{array}{l}\text { MALE } \\
\mathrm{n}=15 \\
\end{array}$ & $\begin{array}{c}R=0.516 ; R^{2}=0.266 \\
p=0.049^{*}\end{array}$ & $\begin{array}{l}\text { MALE } \\
\mathrm{n}=13 \\
\end{array}$ & $\begin{array}{c}R=0.509 ; R^{2}=0.260 \\
p=0.050^{*}\end{array}$ \\
\hline & $\begin{array}{l}\text { FEMALE } \\
\mathrm{n}=14\end{array}$ & $\begin{array}{c}R=0.040 ; R^{2}=0.002 \\
p=0.893\end{array}$ & $\begin{array}{l}\text { FEMALE } \\
\mathrm{n}=12\end{array}$ & $\begin{array}{c}R=0.363 ; R^{2}=0.132 \\
p=0.202\end{array}$ \\
\hline \multirow{2}{*}{ PD48 } & $\begin{array}{l}\text { MALE } \\
\mathrm{n}=16 \\
\end{array}$ & $\begin{array}{c}R=0.202 ; R^{2}=0.041 \\
p=0.454\end{array}$ & $\begin{array}{l}\text { MALE } \\
\mathrm{n}=14\end{array}$ & $\begin{array}{c}R=0.086 ; R^{2}=0.007 \\
p=0.751\end{array}$ \\
\hline & $\begin{array}{l}\text { FEMALE } \\
n=16\end{array}$ & $\begin{array}{c}R=0.378 ; R^{2}=0.143 \\
p=0.149\end{array}$ & $\begin{array}{l}\text { FEMALE } \\
\mathrm{n}=14\end{array}$ & $\begin{array}{c}R=0.194 ; R^{2}=0.038 \\
p=0.471\end{array}$ \\
\hline
\end{tabular}

Table 1. Relationships between BLA-PFC innervation and anxiety-like behavior across development.

Within the PL, there was a significant correlation between BLA innervation and time spent in open arms (highlighted in bold) of the EPM exclusively in males at PD38. Fisher's r-to-z transformation also revealed a significant effect of sex (signified by blue bold typeface). There was also a significant correlation between BLA innervation of the IL and time spent in open arms of the EPM in males at PD38 (bold type). Within the IL, female showed a significant correlation between BLA-PFC innervation and time spent in open arms exclusively at PD28, and Fisher's r-to-z transformation also revealed a trending effect of sex (signified by bold red typeface) at this age. Since there was no significant effect of rearing observed, data was collapsed across rearing groups for correlational analyses presented here. $n$ 's $=12-14$ /age group.

Bold $(p<0.05)$; significant correlation without meeting criterion for significant sex effect Bold and Blue $(p<0.05)$; significant correlation and significant sex difference Bold and Red $(p=0.06)$; significant correlation and trend-level sex difference 
bioRxiv preprint doi: https://doi.org/10.1101/700666; this version posted October 7, 2019. The copyright holder for this preprint (which was not certified by peer review) is the author/funder, who has granted bioRxiv a license to display the preprint in perpetuity. It is made available under aCC-BY-NC-ND 4.0 International license.

Honeycutt et al., 06 OCT 2019 - preprint copy - BioRxiv

A
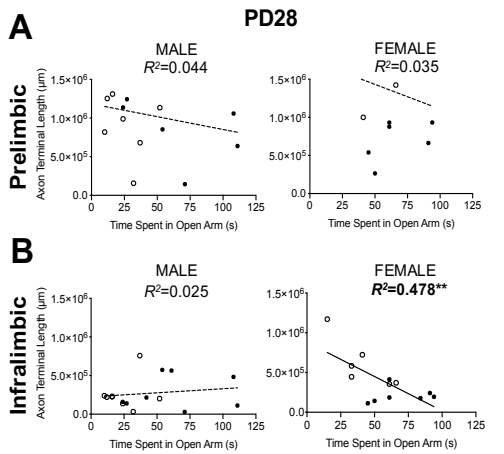

con $\mathrm{O}$ ess

strength of some relationships between innervation and behavior (Table 1). At PD28, higher IL innervation in females was correlated with less time spent in the open arms $\left(R^{2}(14)=0.478 ; p=0.009\right)$ (Fig5B). At PD38, males showed a similar relationship between less time in the open arms and higher PL innervation $\left(R^{2}(13)=0.266 ; p=0.049\right)($ Fig5C) and higher IL innervation $\left(R^{2}(13)=0.260 ; p=0.05\right)$ (Fig5D). No relationships were seen at PD48 (Table 1).

\section{Study 2 Results: rsFC Males}

Two-way ANOVA evaluating BLA-PL rsFC (analyses of these regions were seeded to the BLA; Fig6A-B) with age and rearing revealed no main effect of ELS, but a significant main effect of age $(F=49.9)$ and two regions with an age $x$ rearing interaction in $\mathrm{PL}$ that met threshold criteria $(F=15.8 ; F=28.6)$. Post-hoc showed reduced strength of BLA-PL rsFC from PD28 to PD48 in both $\operatorname{CON}(Z=-3.82)$ and ELS $(Z=-3.26)$. There was no difference in rSFC between CON and ELS at PD48; however, at PD28 CON showed stronger BLA-PL connectivity than ELS ( $Z=-4.13$; Fig6C). A similar 2-way ANOVA evaluating BLA-IL rsFC revealed a significant main effect of age $(F=49.9)$, with no post-hoc differences.

\section{Females}

Two-way ANOVA (age $x$ rearing) for BLA-PL revealed a main effect of age $(F=13.76)$ and rearing $(F=16.10)$, and an interaction $(F=12.65)$. Overall, BLA-PL rsFC decreased from PD28 to PD48 ( $Z=-3.6)$, while ELS females displayed stronger connectivity compared to $\operatorname{CON}(Z=3.5)$. Posthoc showed no difference between CON and ELS at PD28, though a significant difference at PD48 when ELS had stronger BLA-PL connectivity than $\operatorname{CON}(Z=4.83$; Fig6C). CON connectivity decreased from PD28 to PD48 ( $Z=-3.09)$. Conversely, ELS BLA-PL connectivity increased from PD28 to PD48 $(Z=3.46)$.

Two-way ANOVA for BLA-IL rSFC showed no main effect of age or rearing, though an interaction was observed $(F=28.74)$. Overall, BLA-IL rsFC increased from PD28 to PD48 $(Z=3.35)$, and CON generally had weaker connectivity compared to ELS $(Z=-3.79)$. Post-hoc revealed that, at PD48, ELS showed less BLA-IL connectivity than CON (Z = -6.97; Fig6C), and CON showed increased BLA-IL connectivity from PD28 to PD48 ( $Z$ = 4.47), with no significant change seen in ELS.

After noting what appeared to be a lack of typical BLA-PFC rsFC maturation in ELS-exposed females, we then analyzed the effects of sex and rearing on the magnitude of change in BLA-IL rSFC and BLA-PL rSFC between PD28 and PD48. 2-way ANOVA of BLA-IL rSFC revealed a moderate effect size for a trend-level sex $x$ rearing interaction (partial $\eta 2$ $\left.=0.167 ; F_{1,25}=4.09 ; p=0.054\right)$, and post-hoc revealed that females exposed to ELS displayed less PD28-PD48 change compared to CON females ( $p=0.033$ ) (Fig6D). In contrast, no effect of rearing was observed for the magnitude of change in BLA-PL rsFC ( $p=0.78$ ) (Fig6E).
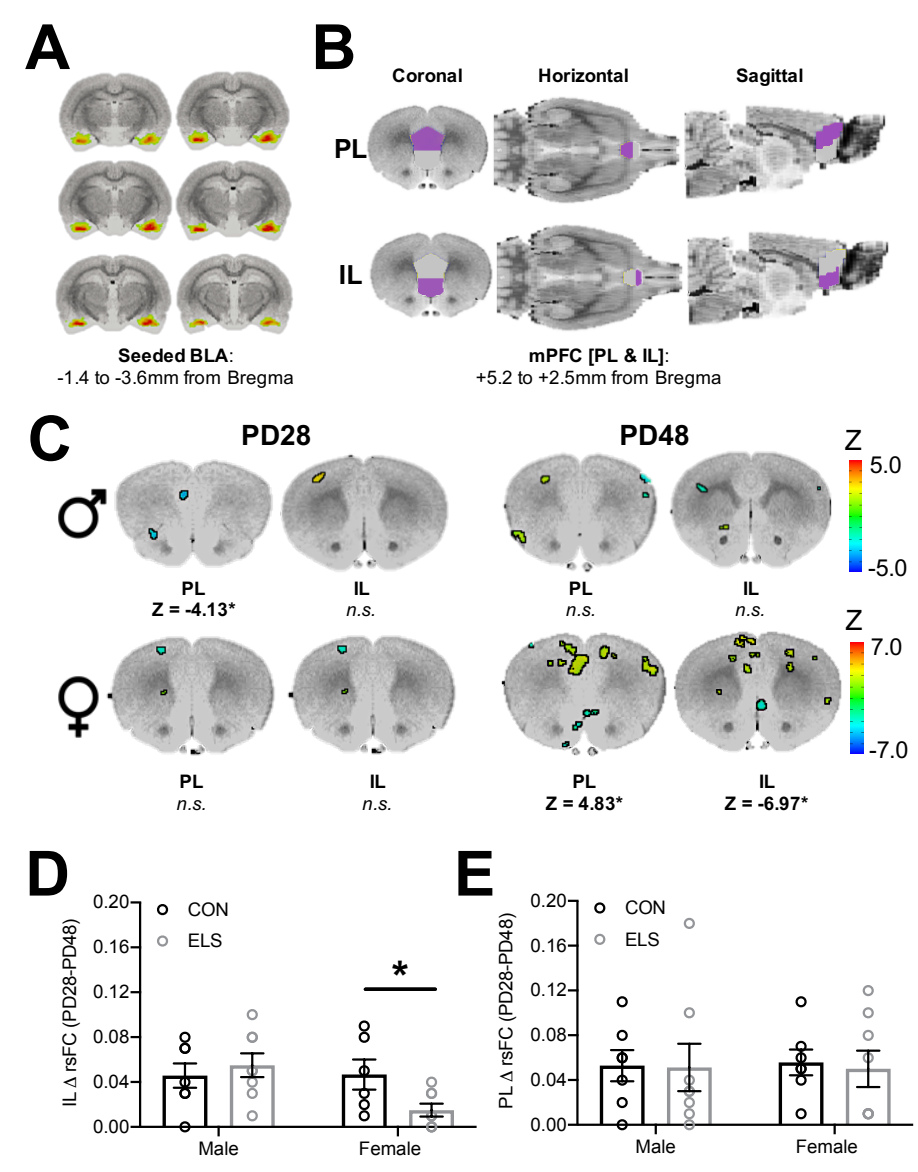

Figure 6. Effects of ELS on BLA-PFC rsFC are sex-specific and endure in females.

Resting state functional connectivity ( $\mathrm{rsFC}$ ) was assessed in a within-subjects manner across development in male and female rats with a history of either CON or ELS rearing with the basolateral amygdala (BLA) as the seeded region (A). The rSFC between the BLA and the mPFC - specifically the prelimbic (PL) and infralimbic (IL) cortices (B) - was assessed. (C) shows results from comparative analyses comparing CON and ELS groups at each age point (PD28 or PD48) in both male and female groups. Colored regions correspond to computed Z values and indicate specific regions within either the PL or IL that met criteria for significance with a minimum cluster size of 30 voxels. Generally, male rats show no group effects of ELS, with the exception of a finding of decreased BLA-PL rSFC in ELS compared to CON groups at PD28. Female rats showed no effect of ELS at PD28, but show striking differences in rsFC in both the PL and IL at PD48 (C). Female, but not male, rats exposed to ELS showed a lack of typical maturation of the IL, evidenced by significantly reduced $\triangle$ rSFC from PD28 to PD48 compared to CON females (D). Conversely, there were no group changes in $\triangle \mathrm{rsFC}$ observed within the $P L(E) . n=7-8$ per group.

$*_{p}<0.05$ 
bioRxiv preprint doi: https://doi.org/10.1101/700666; this version posted October 7, 2019. The copyright holder for this preprint (which was not certified by peer review) is the author/funder, who has granted bioRxiv a license to display the preprint in perpetuity. It is made available under aCC-BY-NC-ND 4.0 International license.

Honeycutt et al., 06 OCT 2019 - preprint copy - BioRxiv

\section{Relationships Between Innervation and Behavior}

Results from all regression analyses of the relationship between behavior on the EPM and functional connectivity are shown in Tables 2 and 3. Fisher's $r$ - to- $z$ transformations revealed an impact of both sex and rearing on relationships between rsFC and behavior at PD28. Significant correlations revealed that in PD28 females exposed to ELS, lower BLA-IL rsFC predicted less time spent in the open arms $\left(R^{2}(8)=\right.$ $0.852 ; p=0.001$ ) (Fig7A); notably, this relationship is juxtaposed with our finding that higher axonal innervation at the same age predicted less time spent in the open arms in all females (Fig5B). Our longitudinal design
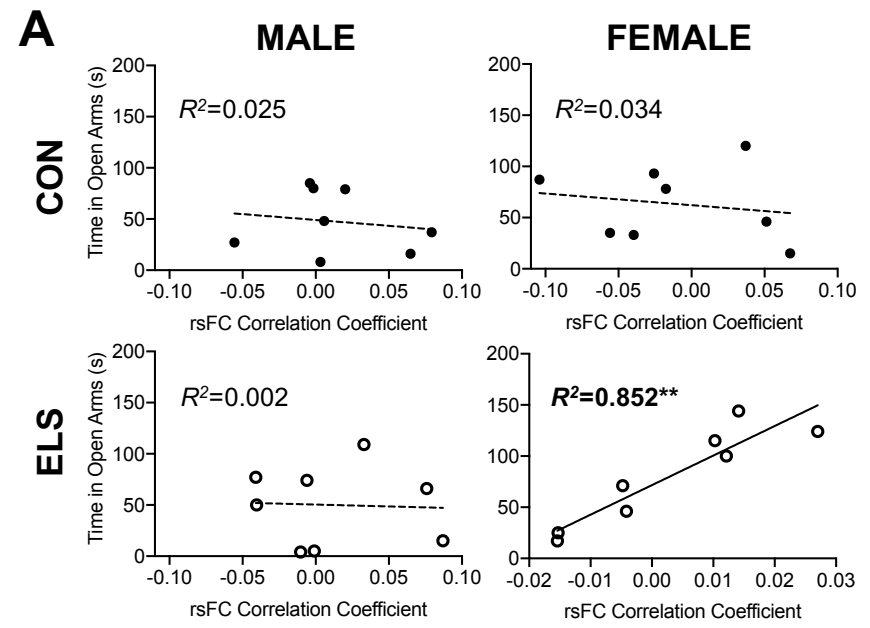

B
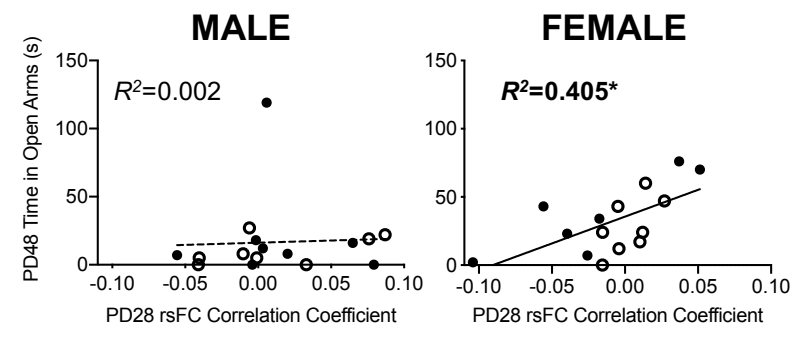

C
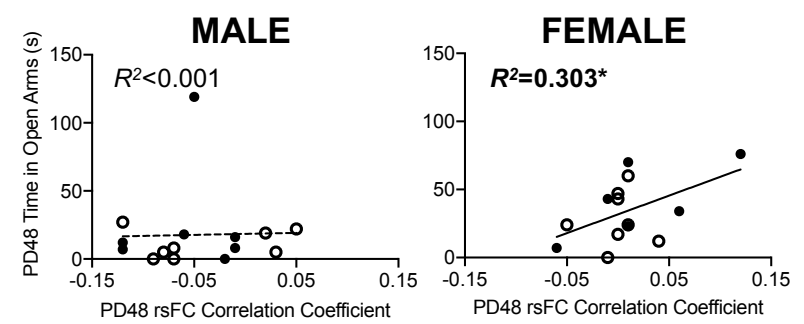

\section{CON O ELS}

Figure 7. ELS significantly impacts the relationship between BLA-IL rsFC and anxiety-like behavior only in females; with PD28 rsFC predictive of PD48 behavior.

Results of linear regression analyses to determine the relationship between BLA-IL rSFC correlation coefficients and performance in the EPM (time spent in open arms (seconds) as an index of anxiety-like behavior) are shown for PD28 in (A). Only females with a history of ELS showed a significant correlation, with higher rsFC correlation coefficients correlating with more time spent in the open arms of the EPM. As this data was conducted over development in a within-subjects manner, we could further explore predictive relationships between these variables. In line with other rsFC data described here, only female rats showed an overarching predictive effect of early/juvenile (PD28) rsFC correlation coefficients on later (PD48) behavior (B). Indeed, females with a higher rsFC correlation coefficients at PD28 exhibited less anxiety-like behavior (as evidenced by increased time spent in open arms). Individual data points for each animal can be seen on the graphs, with black circles representing CON cases, and open circles representing ELS cases, with solid regression lines indicative of significant correlations. $n=7-8$ per group. ${ }^{*} p<0.05 ;{ }^{* *} p<0.01$

\begin{tabular}{|c|c|c|c|c|c|}
\hline & \multicolumn{2}{|c|}{$\begin{array}{l}\text { rsFC BLA-PL vs. } \\
\text { Time in Open }\end{array}$} & \multicolumn{2}{|c|}{$\begin{array}{l}\text { rsFC BLA-IL vs. } \\
\text { Time in Open }\end{array}$} \\
\hline & & MALE & FEMALE & MALE & FEMALE \\
\hline \multirow[b]{2}{*}{ PD28 } & $\begin{array}{l}\mathrm{CON} \\
\mathrm{n} \text { 's }=8\end{array}$ & $\begin{array}{c}R=0.025 ; R^{2}=0.001 \\
p=0.953\end{array}$ & $\begin{array}{c}R=0.212 ; R^{2}=0.045 \\
p=0.615\end{array}$ & $\begin{array}{c}R=0.158 ; R^{2}=0.025 \\
p=0.709\end{array}$ & $\begin{array}{c}R=0.184 ; R^{2}=0.034 \\
p=0.662\end{array}$ \\
\hline & $\begin{array}{l}\text { ELS } \\
\text { n's }=8\end{array}$ & $\begin{array}{c}R=0.328 ; R^{2}=0.108 \\
p=0.427\end{array}$ & $\begin{array}{c}R=0.390 ; R^{2}=0.152 \\
p=0.340\end{array}$ & $\begin{array}{c}R=0.046 ; R^{2}=0.002 \\
p=0.913\end{array}$ & $\begin{array}{c}R=0.923 ; R^{2}=0.852 \\
p=0.001^{*}\end{array}$ \\
\hline PD48 & $n ' s=16$ & $\begin{array}{c}R=0.026 ; R^{2}=0.001 \\
p=0.927\end{array}$ & $\begin{array}{c}R=0.051 ; R^{2}=0.003 \\
p=0.863\end{array}$ & $\begin{array}{c}R=0.001 ; R^{2}<0.001 \\
p=0.996\end{array}$ & $\begin{array}{c}R=0.551 ; R^{2}=0.303 \\
p=0.041\end{array}$ \\
\hline
\end{tabular}

Table 2. Relationships between BLA-PFC rsFC and anxiety-like behavior.

Significant effects of rearing were observed at PD28, but not PD48, therefore analyses were performed separately in CON and ELS at PD28. Significant correlations were only observed between IL and time spent in the open arms of the EPM, and only in females. At PD28, ELS females showed a significant correlation between BLA-IL rSFC and time spent in open arms, and this was also characterized by a significant effect of sex determined by Fisher's r-to-z transformation. At PD48, only females (across both rearing groups) show a significant correlation between BLA-IL rsFC and time spent in open arms. $n$ 's $=8$ for PD28 groups; $n^{\prime} s=16$ for PD48 groups.

Bold $(p<0.05)$; significant correlation without meeting criterion for significant sex effect Bold and Orange $(p<0.05)$; significant correlation and significant effect of sex Asterisk $(*)$ designates a significant effect of rearing $(p<0.05)$ within each sex.

PD48 Time Spent in Open vs.

PD28 rsFC BLA-PL

PD28 rsFC BLA-IL

\begin{tabular}{lc|lc}
\hline MALE & $R=0.354 ; R^{2}=0.125$ & MALE & $R=0.049 ; R^{2}=0.002$ \\
$\mathrm{n}=16$ & $p=0.178$ & $\mathrm{n}=16$ & $p=0.856$ \\
\hline FEMALE & $R=0.428 ; R^{2}=0.175$ & FEMALE & $\boldsymbol{R}=\mathbf{0 . 6 3 7 ;} \boldsymbol{R}^{2}=\mathbf{0 . 4 0 5}$ \\
$\mathrm{n}=15$ & $p=0.107$ & $\mathrm{n}=15$ & $\boldsymbol{p}=\mathbf{0 . 0 1 1 ^ { * }}$ \\
\hline
\end{tabular}

Table 3. Predictive relationships between PD28 BLA-PFC rsFC and PD48 anxiety-like behavior.

Within the IL, there was a significant correlation between female PD28 rsFC correlation coefficient and later PD48 time spent in open arms in the EPM, thereby suggesting a predictive value of early rsFC measures and later behavior. Since there were no effects of rearing observed, data was collapsed across rearing groups.

Bold $(p<0.05)$; significant correlation without meeting criterion for significant sex effect

further allowed the analysis of early rsFC with later adolescent behavior. In all females, lower BLA-IL rsFC at PD28 also predicted less time spent in the open arms twenty days later at PD48 $\left(R^{2}(7)=0.405 ; p=0.011\right)$, suggesting an enduring and predictive relationship in females (Fig7B). This enduring relationship in females was also seen in a significant relationship between lower BLA-IL rSFC at PD48 and less time in the open arms at the same age (Fig 7C; $R^{2}(13)=0.303 ; p=0.041$ ).

\section{Discussion}

This work describes sex-specific neuroanatomical etiology and corresponding functional maturation of the BLA-PFC circuit following ELS. The data reveal newly uncovered aberrations to PFC innervation that can be interpreted in the context of atypical behavior and FC that has been observed in humans (Gee et al., 2013a; Philip et al., 2013; Teicher et al., 2016; Thomason et al., 2015) and in animals (Johnson et al., 2018; Yan et al., 2017). We observed sex- and age-dependent effects on BLA innervation in PL and IL regions of the PFC following ELS in a rat model of caregiver deprivation. Our findings suggest that females may be particularly vulnerable to neuroanatomical consequences of early adversity, with innervation effects seen earlier in females compared to a later effect observed in males. This is in line with human studies describing sex-dependent effects of early adversity where female participants appear to exhibit more severe adolescent and later-life consequences, especially with regard to affective disorders (Humphreys et al., 2015).

Our data indicate that BLA-IL innervation increases through adolescence in a bilaminar manner across development, with the most dramatic increases following ELS in both males and females. Importantly, these main effects of age support previous work in male rats (Cunningham et al., 2002) and now characterize a similar trajectory in 
bioRxiv preprint doi: https://doi.org/10.1101/700666; this version posted October 7, 2019. The copyright holder for this preprint (which was not certified by peer review) is the author/funder, who has granted bioRxiv a license to display the preprint in perpetuity. It is made available under aCC-BY-NC-ND 4.0 International license.

Honeycutt et al., 06 OCT 2019 - preprint copy - BioRxiv

female rats. While IL innervation showed a developmental increase through adolescence, PL innervation appeared to reach adult-like levels in both sexes earlier than was captured presently (Bouwmeester et al., 2002; Van Eden and Uylings, 1985). Following ELS, however, our data indicate that aberrant effects on innervation were apparent at PD28 in females, but not until PD38 in males; this finding was observed across both the PL and IL. However, while ELS conferred a similar agedependent influx of BLA axonal innervation in both regions, the longterm neuroanatomical alterations were different depending on region examined. Indeed, in PL we saw a transient effect of ELS that was ageand sex-dependent. In IL, however, there was evidence of precocial maturation, such that ELS induced BLA-IL innervation that was comparable to more mature (PD48) patterns in female juveniles (PD28) and male early adolescents (PD38). In fact, throughout the mPFC we observed that both male and female rats showed an unexpected transient spike in innervation that appeared to resolve at the following developmental timepoint. It is possible that reversal of the innervation seen at earlier time points may be due to pruning mechanisms (Koss et al., 2013) that typically occur in adolescence, and these mechanisms may serve to mediate excess innervation (Rakic et al., 1994; Riccomagno and Klodkin, 2016; Spear, 2000). Prior work has shown a peak in BLA-PL connectivity, specifically at PD30 (Pattwell et al., 2016), that may contribute to the present findings of transient ELS-exacerbated hyperinnervation. However, this does not explain why innervation to the IL spiked at PD28, was reduced to CON levels at PD38, and then spiked again by PD48 in female ELS. It is possible that the temporary (one week) isolation following surgery may have acted as a secondary stressor acting in conjunction with pubertal changes to produce a resurgence of this ELSspecific phenotype (Andersen and Teicher, 2008; Tzanoulinou and Sandi, 2016). Relatedly, surgery itself during peripubertal development compared to other time periods may have differentially interacted with ELS.

Importantly, the ages at which ELS-exposed females and males first displayed increased BLA-IL innervation (PD28 and PD38, respectively) were the ages at which higher innervation correlated with higher anxietylike behavior (less time spent in open arms of the EPM). Since monosynaptic input from the BLA to the medial PFC drives aversion to anxiogenic stimuli as measured in the EPM (Felix-Ortiz, 2016), these data suggest that hypertrophic effects of ELS at the BLA-IL circuit lead to heightened anxiety-like behavior in ELS-exposed animals. However, we were surprised that group-wise comparisons only showed higher anxietylike behaviors in ELS females at PD38, but not at PD28 when innervation was increased (Fig4). Group comparisons also failed to reveal higher anxiety-like behaviors in ELS-exposed males at any age. Our group and others have previously observed increased anxiety-like behaviors in male and female rats following ELS (e.g., Ganguly et al., 2015, Holland et al., 2013, Jin et al., 2018), therefore further work will reveal whether more sensitive assays can more reliably demonstrate anxiety-like behavior in ELS-exposed rats. Here we demonstrate that, regardless of mean differences, ELS experience can forge a relationship between heightened innervation and anxiety-like behavior at distinct developmental timepoints that could suggest mechanistic ties between early hypertrophy of inputs and behavior.

Transient effects of ELS on innervation and behavior are notable because adolescent perturbations have been shown to have lasting consequences on later life function. Multiple lines of evidence from both clinical and animal studies suggest that physiological or experiential anomalies during critical periods of development can program the central nervous system for susceptibility or resilience to future environments (Andersen, 2003; Nederhof and Schmidt, 2012). One example is seen with an animal model using prenatal treatment with the mitotoxin MAM, which produces adolescent-specific corticolimbic and mesolimbic dysfunctions that drive a hyperresponsivity to stress with anxiety-like and psychosis-like behavior. If conversion to the dysfunctional phenotype in adolescence is prevented by relieving stress in adolescence, MAM-treated animals will still be more susceptible to affective dysfunction in adulthood (Gomes et al., 2019). Moreover, ELS reportedly leads to adolescent alterations in PFC NMDA receptor subunit composition that regulate anxiety-like behaviors in males (Ganguly et al., 2015); future work will reveal whether increased glutamatergic input from the BLA drives these receptor changes in the PFC. Since the PFC can serve reciprocally as a modulator of BLA activity (Rosenkranz and Grace, 2002), it is therefore possible that transient innervation changes lead to long-term receptor alterations and subsequent changes to the efficiency of BLA-PFC functional connectivity. Together, the early increases in innervation after ELS reported here may perturb normal critical period maturation, leading to late-onset effects on functional connectivity and affective dysregulation.

The results from the rSFC analyses in females supported the idea that early maturation of BLA-IL innervation disrupted the later functional relationship between these regions (Tottenham and Galván, 2016). Specifically, females exposed to ELS displayed dampened maturation of BLA-IL rsFC compared to female CON; while no effects of rearing were apparent at PD28, ELS female rats failed to display the increase in BLA-IL rsFC by PD48 that was observed in female CON. This is in line with previous work showing that BLA-mPFC connectivity is grossly unchanged at pre-weaning following a limited bedding model (Guadagno et al., 2018), while rsFC later in life can be altered following ELS (Nephew et al., 2017). Interestingly, increased [more mature] rsFC BLA-IL connectivity in female ELS at PD28 correlated with decreased anxiety-like behavior at that age as well as 20 days later. This suggests that more mature connectivity in female juveniles may confer enduring behavioral resilience, which is consistent with previous reports that dampened connectivity is associated with increased anxiety in adolescence (Kim et al., 2011; Nooner et al., 2013). While ELS exposure in males appeared to result in lower juvenile (PD28) rsFC between the BLA and the PL, no effects on the magnitude of change between PD28-PD48 were noted, therefore altered maturation per se was not observed. Interestingly, ELS affected male BLA-PL rsFC at an age that preceded any ELS-attributable increased innervation, suggesting that the reciprocal connectivity between the two regions was altered without the influence of aberrant amygdalofugal innervation.

ELS experience resulted in dampened maturation of BLA-IL rSFC in females, in contrast to the precocial maturation we observed in axonal innervation of the IL from the BLA, as well as the accelerated maturation of task-based FC reported following childhood maltreatment in humans (Gee et al., 2013a). While BLA-mPFC rsFC in humans has been observed to increase towards more positive connectivity through adolescent development (Gabard-Durnam et al., 2014), task-based FC during fearful face presentations declines from positive connectivity to a negative connectivity (Gee et al., 2013b). This task-based FC was further found to reach mature (more negative) levels in previously institutionalized children (Gee et al., 2013a). In contrast, girls who express higher basal cortisol levels at 4.5 years display lower rsFC between the ventromedial PFC and the amygdala at 18 years (Burghy et al., 2012), corroborating our current findings in PD48 females (Fig6). rsFC reflects an intrinsic alternate resonance between different brain areas connected at large scale, in contrast to the more isolated activation of the corresponding brain areas during a task (Rasero et al., 2018). Therefore, it appears that early hyperinnervation to the PFC may alter the stability of the functional BLAPFC network as it develops, leading to increased anxiety when innervation arises and disrupted maturation of rsFC; how these effects in rats relate to task-based $\mathrm{FC}$ is currently unknown. It is also possible that early maturation of BLA-PFC projections may overwhelm the slow- 
bioRxiv preprint doi: https://doi.org/10.1101/700666; this version posted October 7, 2019. The copyright holder for this preprint (which was not certified by peer review) is the author/funder, who has granted bioRxiv a license to display the preprint in perpetuity. It is made available under aCC-BY-NC-ND 4.0 International license.

\section{Honeycutt et al., 06 OCT 2019 - preprint copy - BioRxiv}

maturing reciprocal projections to the BLA that dampen anxiety-related circuit activity in mature brains (Arruda-Carvalho et al., 2017; Selleck et al., 2018).

The present findings support previous work indicating the distinct functional relationship between the BLA and PL and IL regions of MPFC (Calhoon and Tye, 2015), with PL connectivity related to anxiogenic effects (Felix-Ortiz et al., 2016) and IL connectivity promoting anxiolytic effects (Maroun et al., 2012). Furthermore, these findings are in line with the idea that altered neuroanatomy and functionality of PL and IL, along with BLA, likely have reciprocal effects on one another, further contributing to the exacerbation of ELS-induced anxiety-like phenotypes in adolescence and early adulthood (Likhtik and Paz, 2015; Zimmermann et al., 2019).

Taken together, maternal separation in rats was found to disrupt normative development of both anatomical (axonal innervation) and functional ( $\mathrm{rSFC}$ ) connectivity within a circuit regulating emotional processing, with sex-specific effects and evidence of resilience in individuals with precocial maturation of rsFC. These findings have implications for intervention based on experience, age, and sex - three functionally interactive factors that uniquely define risk in every individual.

\section{Acknowledgements}

The authors would like to sincerely thank Dr. Jens Foell (Florida State University) and Dr. Michael Rohan (McLean Hospital) for their feedback and suggestions for rSFC figures for this manuscript.

\section{Funding}

This work was funded by a grant from the NIMH (1R01MH107556-01) awarded to HCB.

\section{Disclosures}

CRF has a financial interest in Animal Imaging Research, the company that makes the rat imaging system. All other authors have no conflicts of interest to disclose.

\section{References}

Alarcón G, Cservenka A, Rudolph MD, Fair DA, Nagel BJ (2015). Developmental sex differences in resting state functional connectivity of amygdala sub-regions. Neuroimage 115: 235-244. DOI: 10.1016/j.neuroimage.2015.04.013

Andersen SL (2003). Trajectories of brain development: point of vulnerability or window of opportunity? Neurosci Biobehav Rev 27(1-2): 3-18. DOI: 10.1016/S0149-7634(03)00005-8

Andersen SL, Teicher MH (2008). Stress, sensitive periods and maturational events in adolescent depression. Trends Neurosci 31(4): 183-191. DOI: 10.1016/j.tins.2008.01.004

Arruda-Carvalho M, Wu WC, Cummings KA, Clem RL (2017). Optogenetic examination of prefrontal-amygdala synaptic development. J Neurosci 37(11): 2976-2985. DOI: 10.1523/JNEUROSCI.3097-16.2017

Bangasser DA, Valentino RJ (2014). Sex differences in stress-related psychiatric disorders: neurobiological perspectives. Front Neuroendocrinol 35(3): 303319. DOI: 10.1016/j.yfrne.2014.03.008

Bouwmeester H, Wolterink G, Van Ree JM (2002). Neonatal development of projections from the basolateral amygdala to prefrontal, striatal, and thalamic structures in the rat. Journal of Comparartive Neurology 442(3): 239-249. DOI: 10.1002/cne.10084

Burghy CA, Stodola DE, Ruttle PL, Molloy EK, Armstrong JM, Oler JA, Fox ME, Hayes AS, Kalin NH, Essex MJ, Davidson RJ, Birn RM (2012). Developmental pathways to amygdala-prefrontal function and internalizing symptoms in adolescence. Nat Neurosci 15(12): 1736-1741. DOI: 10.1038/nn.3257

Calhoon GG, Tye KM (2015). Resolving the neural circuits of anxiety. Nat Neurosci 18(10): 1394-1404. DOI: 10.1038/nn.4101
Callaghan BL, Richardson R (2011). Maternal separation results in early emergence of adult-like fear and extinction learning in infant rats. Behav Neurosci 125: 20-28. DOI: 10.1037/a0022008

Callaghan BL, Tottenham N (2016). The stress acceleration hypothesis: effects of early-life adversity on emotion circuits and behavior. Current Opinion in Behavioral Sciences 7: 76-81. DOI: 10.1016/j.cobeha.2015.11.018

Choi J, Jeong B, Rohan ML, Polcari AM, Teicher MH (2009). Preliminary evidence for white matter tract abnormalities in young adults exposed to parental verbal abuse. Biol Psychiatry 65(3): 227-234. DOI: 10.1016/j.biopsych.2008.06.022

Coley EJL, Demaestri C, Ganguly P, Honeycutt JA, Peterzell S, Rose N, Ahmed N, Holschbach M, Trivedi M, Brenhouse HC (2019). Cross-generational transmission of early life stress effects on HPA regulators and Bdnf are mediated by sex, lineage, and upbringing. Front Behav Neurosci 13:101. DOI: 10.3389/fnbeh.2019.00101

Cunningham MG, Bhattacharyya S, Benes FM (2002). Amygdalo-cortical sprouting continues into early adulthood: implications for the development of normal and abnormal function during adolescence. J Comp Neurol 453(2): 116-130. DOI: $10.1002 /$ cne.10376

Davis EP, Pfaff D (2014). Sexually dimorphic responses to early adversity: implications for affective problems and autism spectrum disorder. Psychoneuroendocrinology 49: 11-25. DOI: 10.1016/j.psyneuen.2014.06.014

Dickie EW, Armony JL (2008). Amygdala responses to unattended fearful faces: interaction between sex and trait anxiety. Psychiatry Research: Neuroimaging 162: 51-57. DOI: 10.1016/j.pscychresns.2007.08.002

Farrell MR, Holland FH, Shansky RM, Brenhouse HC (2016). Sex-specific effects of early life stress of social interaction and prefrontal cortex dendritic morphology in young rats. Behav Brain Res 310: 119-125. DOI: 10.1016/j.bbr.2016.05.009

Felix-Ortiz AC, Burgos-Robles A, Bhagat ND, Leppla CA, Tye KM (2016). Bidirectional modulation of anxiety-related and social behaviors by amygdala projections to the medial prefrontal cortex. Neuroscience 321: 197-209. DOI: 10.1016/j.neuroscience.2015.07.041

Gabard-Durnam L, Flannery J, Goff B, Gee DG, Humphreys KL, Telzer E, Hare T, Tottenham N (2014). The development of the human amygdala functional connectivity at rest from 4 to 23 years: a cross-sectional study. Neuroimage 95: 193-207. DOI: 10.1016/j.neuroimage.2014.03.038

Gabard-Durnam LJ, Gee DG, Goff B, Flannery J, Telzer E, Humphreys KL, et al. (2016). Stimulus-elicited connectivity influences resting-state connectivity years later in human development: a prospective study. J Neurosci 36(17):4771-4781. DOI: 10.1523/JNEUROSCI.0598-16.2016

Ganguly P, Holland FH, Brenhouse HC (2015). Functional uncoupling NMDAR NR2A subunit from PSD-95 in the prefrontal cortex: effects on behavioral dysfunction and parvalbumin loss after early-life stress. Neuropsychopharmacology 40(12): 2666-2675. DOI: 10.1038/npp.2015.134

Ganguly P, Honeycutt JA, Rowe JR, Demaestri C, Brenhouse HC (2019). Effects of early life stress on cocaine conditioning and AMPA receptor composition are sex-specific and driven by TNF. Brain Behav Immun 78: 41-51. DOI: 10.1016/j.bbi.2019.01.006

Gee DG, Gabard-Durnam LJ, Flannery J, Goff B, Humphreys KL, Telzer EH, et al. (2013a). Early developmental emergence of human amygdala-prefrontal connectivity after maternal deprivation. Proc Natl Acad Sci USA 110(39): 15638-15643. DOI: 10.1073/pnas.1307893110

Gee DG, Humphreys KL, Flannery J, Goff B, Telzer EH, Shapiro M, Hare TA, Bookheimer SY, Tottenham N (2013b). A developmental shift from positive to negative connectivity in human amygdala-prefrontal circuitry. J Neurosci 33(10): 4584-4593. DOI: 10.1523/JNEUROSCI.3446-12.2013

Gomes FV, Zhu X, Grace AA (2019). Stress during critical periods of development and risk for schizophrenia. Schizophrenia Research pii: S09209964(19)30020-9. DOI: 10.1016/j.schres.2019.01.030

Grassi-Oliveira R, Honeycutt JA, Holland FH, Ganguly P, Brenhouse HC (2016). Cognitive impairment effects of early life stress in adolescents can be predicted with early biomarkers: impacts of sex, experience, and cytokines. Psychoneuroendocrinology 19-30. 71: DOI: 10.1016/j.psyneuen.2016.04.016

Guadagno A, Kang MS, Devenyi GA, Mathieu AP, Rosa-Neto P, Chakravarty M, Walker DM (2018). Reduced resting-state functional connectivity of the basolateral amygdala to the medial prefrontal cortex in preweaning rats 
bioRxiv preprint doi: https://doi.org/10.1101/700666; this version posted October 7, 2019. The copyright holder for this preprint (which was not certified by peer review) is the author/funder, who has granted bioRxiv a license to display the preprint in perpetuity. It is made available under aCC-BY-NC-ND 4.0 International license.

Honeycutt et al., 06 OCT 2019 - preprint copy - BioRxiv

exposed to chronic early-life stress. Brain Structure and Function 223(8): 3711-3729. DOI: 10.1007/s00429-018-1720-3

Gundersen HJG, Jensen EB (1987). The efficiency of systematic sampling in stereology and its prediction. Journal of Microscopy 147(3): 229-263. DOI: 10.1111/j.1365-2818.1987.tb02837.x

Gundersen HJG, Vedel Jensen EB, Kieu K, Nielsen J (1999). The efficiency of systematic sampling in stereology--reconsidered. Journal of Microscopy 193(3): 199-211. DOI: 10.1046/j.1365-2818.1999.00457.x

Hammen C, Henry R, Daley SE (2000). Depression and sensitization to stressors among young women as a function of childhood adversity. Journal of Counseling and Clinical Psychology 68(5): 782-787. DOI: 10.1037/0022006X.68.5.782

Hane AA, Fox NA (2016). Early caregiving and human biobehavioral development: a comparative physiology approach. Current Opinion in Behavioral Sciences 7: 82-90. DOI: 10.1016/j.cobeha.2015.12.002

Heim C, Newport DJ, Mletzko T, Miller AH, Nemeroff CB (2008). The link between childhood trauma and depression: insights from HPA axis studies. Psychoneuroendocrinology 33(6): 693-710. DOI: 10.1016/j.psyneuen.2008.03.008

Herringa RJ, Birn RM, Ruttle PL, Burghy CA, Stodola DE, Davidson RJ, Essex MJ (2013). Childhood maltreatment is associated with altered fear circuitry and increased internalizing symptoms in late adolescence. Proc Natl Aca Sci USA 110(47): 19119-19124. DOI: 10.1073/pnas.1310766110

Humphreys KL, Gleason MM, Drury SS, Miron D, Nelson CA, Fox NA, Zeanah CH (2015). Effects of institutional rearing and foster care on psychopathology at age 12 years in Romania: follow-up of an open, randomized controlled trial. Lancet Psychiatry 2(7): 625-634. DOI: 10.1016/S2215-0366(15)00095-4

Jin S, Zhao Y, Jiang Y, Wang Y, Li C, Zhang D, Lian B, Du Z, Sun H, Sun L (2018). Anxiety-like behaviour assessments of adolescent rats after repeated maternal separation during early life. Neuroreport 29(8): 643-649. DOI: 10.1097/WNR.0000000000001010

Johnson FK, Delpech JC, Thompson GJ, Wei L, Hai J, Herman P, Hyder F, Kaffman A (2018). Amygdala hyper-connectivity in a mouse model of unpredictable early life stress. Translational Psychiatry 8: 49. DOI: 10.1038/s41398-0180092-z

Kaiser RH, Clegg R, Goer F, Pechtel P, Beltzer M, Vitaliano G, Olson SP, Teicher MH, Pizzagalli DA (2018). Childhood stress, grown-up brain networks: corticolimbic correlates of threat-related early life stress and adult stress response. Psychol Med 48(7): 1157-1166. DOI: 10.1017/S0033291717002628

Killgore WD, Britton JC, Schwab ZJ, Price LM, Weiner MR, Gold AL, et al. (2014). Cortico-limbic responses to masked affective faces across ptsd, panic disorder, and specific phobia. Depress Anxiety 31(2): 150-159. DOI: 10.1002/da.22156

Kim MJ, Gee DG, Loucks RA, Davis FC Whalen PJ (2011). Anxiety dissociates dorsal and ventral medial prefrontal cortex functional connectivity with the amygdala at rest. Cereb Cortex 21(7): 1667-1673. DOI: 10.1093/cercor/bhq237

Koss WA, Belden CE, Hristov AD, Juraska JM (2013). Dendritic remodeling in the adolescent medial prefrontal cortex and the basolateral amygdala of male and female rats. Synapse 68(2): 61-72. DOI: 10.1002/syn.21716

Krugers HJ, Arp JM, Xiong H, Kanatsou S, Lesuis SL, Korosi A, et al. (2017). Early life adversity: lasting consequences for emotional learning. Neurobiology of Stress 6: 14-21. DOI: 10.1016/j.ynstr.2016.11.005

Lenroot RK, Gogtay N, Greenstein DK, Wells EM, Wallace GL, Clasen LS, et al. (2007). Sexual dimorphism of brain developmental trajectories during childhood and adolescence. Neurolmage 36(4): 1065-1073. DOI: 10.1016/j.neuroimage.2007.03.053

Lenroot RK, Giedd JN (2010). Sex differences in the adolescent brain. Brain Cogn 72: 46-55. DOI: 10.1016/j.bandc.2009.10.008

Likhtik E, Paz R (2015). Amygdala-prefrontal interavtions in (mal)adaptive learning. Trends Neurosci 38(3): 158-166. DOI: 10.1016/j.tins.2014.12.007

Lupien SJ, McEwan BS, Gunnar MR, Heim C (2009). Effects of stress throughout the lifespan on the brain, behaviour and cognition. Nature Reviews Neuroscience 10: 434-445. DOI: 10.1038/nrn2639

Maccari S, Kruggers, HJ, Morley-Fletcher S, Szyf M, Brunton PJ (2014). The consequences of early-life adversity: neurobiological, behavioural and epigenetic adaptations. I Neuroendocrinol 26(10): 707-723. DOI: 10.1111/jne.12175
Maroun M, Kavushansky A, Holmes A, Wellman C, Motanis H (2012). Enhanced extinction of aversive memories by high-frequency stimulation of the rat infralimbic cortex. PLoS ONE 7: e35853. DOI: 10.1371/journal.pone.0035853

Martin L, Viljoen M, Kidd M, Seedat S (2014). Are childhood trauma exposures predictive of anxiety sensitivity in school attending youth? J Affect Disord 168: 5-12. DOI: 10.1016/j.jad.2014.06.035

McEwen BS (2008). Understanding the potency of stressful early life experiences on brain and body function. Metabolism 57: s11-s15. DOI: 10.1016/j.metabol.2008.07.006

McGaugh JL (2004). The amygdala modulates the consolidation of memories of emotionally arousing experiences. Annu Rev Neurosci 27: 1-28. DOI: 10.1146/annurev.neuro.27.070203.144157

Mouton PR, Gokhale AM, Ward NL, West MJ (2002). Stereological length estimation using spherical probes. Journal of Microscopy 206: 54-64. DOI: 10.1046/j.1365-2818.2002.01006.x

Nederhof E, Schmidt MV (2012). Mismatch or cumulative stress: toward an integrated hypothesis of programming effects. Physiol Behav 106(5): 691700. DOI: 10.1016/j.physbeh.2011.12.008

Nephew BC, Huang W, Poirier GL, Payne GL, Jing JA (2017). Altered neural connectivity in adult female rats exposed to early life social stress. Behav Brain Res 316:225-233. DOI: 10.1016/j.bbr.2016.08.051

Nooner KB, Mennes M, Brown S, Castellanos FX, Leventhal B, Milham MP, Colcombe SJ (2013). Relationship of trauma symptoms to amygdala-based functional brain changes in adolescents. J Trauma Stress 26(6): 784-787. DOI: $10.1002 /$ jts.21873

Ono M, Kikusui T, Sasaki N, Ichikawa M, Mori Y, Murakami-Murofushi K (2008). Early weaning induces anxiety and precocious myelination in the anterior part of the basolateral amygdala of Balb/c mice. Neuroscience 156(4): 11031110. DOI: 10.1016/j.neuroscience.2008.07.078

Pattwell SS, Liston C, Jing D, Ninan I, Yang RR, Witztum J, et al. (2016). Dynamic changes in neural circuitry during adolescence are associated with persistent attenuation of fear memories. Nature Communications 7: 11475. DOI: 10.1038/ncomms 11475

Paxinos G, Watson C (1997). The rain brain in stereotaxic coordinates. Academic Press, New York.

Philip NS, Kuras YI, Valentine TR, Sweet LH, Tyrka AR, Price LH, Carpenter LL (2013). Regional homogeneity and resting state functional connectivity: Associations with exposure to early life stress. Psychiatry Research: Neuroimaging 214(3): 247-253. DOI: 10.1016/j.pscychresns.2013.07.013

Rakic P, Bourgeois JP, Goldman-Rakic PS (1994). Synaptic development of the cerebral cortex: implications for learning, memory, and mental illness. Progress in Brain Research 102: 227-243. DOI: 10.1016/S00796123(08)60543-9

Rasero J, Aerts H, Ontivero Ortega M, Cortes JM, Stramaglia S, Marinazzo D (2018). Predicting functional networks from region connectivity profiles in taskbased versus resting-state fMRI data. PLoS One 13(11): e0207385. DOI: 10.1371/journal.pone. 0207385

Riccomagno MM, Klodkin AL (2016). Sculpting neural circuits by axon and dendrite pruning. Annu Rev Cell Dev Biol 31: 779-805. DOI: 10.1146/annurev-cellbio100913-013038

Rosenkranz JA, Grace AA (2002). Cellular mechanisms of infralimbic and prelimbic prefrontal cortical inhibition and dopaminergic modulation of basolateral amygdala neurons in vivo. J Neurosci 22: 324-337. DOI: 10.1523/JNEUROSCI.22-01-00324.2002

Schoenbaum G, Chiba AA, Gallagher M (2000). Changes in functional connectivity in orbitofrontal cortex and basolateral amygdala during learning and reversal training. J Neurosci 20(13): 5179-5189. DOI: 10.1523/JNEUROSCI.20-1305179.2000

Selleck RA, Xhang W, Samberg HD, Padival M, Rosenkranz JA (2018). Limited prefrontal cortical regulation over the basolateral amygdala in adolescent rats. Sci Rep 8: 17171. DOI: 10.1038/s41598-018-35649-0

Senn V, Wolff SB, Herry C, Grenier F, Ehrlich I, Gründemann J, et al. (2014). Longrange connectivity defines behavioral specificity of amygdala neurons. Neuron 81(2): 428-437. DOI: 10.1016/j.neuron.2013.11.006

Smyke AT, Koga SF, Johnson DE, Fox NA, Marshall PJ, Nelson CA, Zeanah CH, BEIP Core Group (2007). The caregiving context in institution-reared and familyreared infants and toddlers in Romania. J Child Psychol Psychiatry 48(2): 210218. DOI: 10.1111/j.1469-7610.2006.01694.x 
bioRxiv preprint doi: https://doi.org/10.1101/700666; this version posted October 7, 2019. The copyright holder for this preprint (which was not certified by peer review) is the author/funder, who has granted bioRxiv a license to display the preprint in perpetuity. It is made available under aCC-BY-NC-ND 4.0 International license.

\section{Honeycutt et al., 06 OCT 2019 - preprint copy - BioRxiv}

Spear LP (2000). The adolescent brain and age-related behavioral manifestations. Neurosci Biobehav Rev 24(4): 417-463. DOI: 10.1016/S01497634(00)00014-2

St Onge JR, Stopper CM, Zahm DS, Floresco SB (2012). Separate prefrontalsubcortical circuits mediate different components of risk-based decision making. J Neurosci 32(8): 2886-2899. DOI: 10.1523/JNEUROSCI.562511.2012

Swanson LW (2018). Brain maps 4.0-structure of the rat brain: an open access atlas with global nervous system nomenclature ontology and flatmaps. J Comp Neurol 526(6): 935-943. DOI: 10.1002/cne.24381

Teicher MH, Samson JA, Anderson CM, Ohashi K (2016). The effects of childhood maltreatment on brain structure, function and connectivity. Nature Reviews Neuroscience 17: 652-666. DOI: 10.1038/nrn.2016.111

Thomason ME, Dennis EL, Joshi AA, Joshi SH, Dinov ID, Chang C, et al. (2011a). Resting-state $\mathrm{fMRI}$ can reliably map neural networks in children. Neuroimage 55: 165-175. DOI: 10.1016/j.neuroimage.2010.11.080

Thomason ME, Hamilton JP, Gotlib IH (2011b). Stress-induced activation of the HPA axis predicts connectivity between subgenual cingulate and salience network during rest in adolescents. J Child Psychol Psychiatry 52(10): 10261034. DOI: 10.1111/j.1469-7610.2011.02422.x

Thomason ME, Marusak HA, Tocco MA, Vila AM, McGarragle O, Rosenberg DR (2015). Altered amygdala connectivity in urban youth exposed to trauma. Social Cognitive and Affective Neuroscience 10(11): 1460-1468. DOI: $10.1093 /$ scan/nsv030

Tottenham N, Galván A (2016). Stress and the adolescent brain: amygdalaprefrontal cortex circuitry and ventral striatum as developmental targets. Neurosci Biobehav Rev 70: 217-227. DOI: 10.1016/j.neubiorev.2016.07.030

Tyrka AR, Burgers DE, Philip NS, Price LH, Carpenter LL (2013). The neurobiological correlates of childhood adversity and implications for treatment. Acta Psychiatr Scand 128(6): 434-447. DOI: 10.1111/acps.12143
Tzanoulinou S, Sandi C (2016). The programming of the social brain by stress during childhood and adolescence: from rodents to humans. Social Behavior from Rodents to Humans. In Wöhr M, Krach S (eds) Social Behavior from Rodents to Humans. Current Topics in Behavioral Neurosciences, vol 30. Springer, Cham. DOI: 10.1007/7854_2015_430

Van Eden CG, Uylings HB (1985). Cytoarchitectonic development of the prefrontal cortex in the rat. J Comp Neurol 241: 253-267. DOI: 10.1002/cne.902410302

Van Tieghem MR, Tottenham N (2018). Neurobiological programming of early life stress: functional development of amygdala-prefrontal circuitry and vulnerability for stress-related psychopathology. Curr Topics in Behav Neurosci 38: 117-136. DOI: 10.1007/7854_2016_42

Wainwright NW, Surtees PG (2002). Childhood adversity, gender and depression over the life-course. J Affect Disord 72: 33-44. DOI: 10.1016/s01650327(01)00420-7

Wieck A, Andersen SL, Brenhouse HC (2013). Evidence for a neuroinflammatory mechanism in delayed effects of early life adversity in rats: relationship to cortical NMDA receptor expression. Brain Behav Immun 28: 218-226. DOI: 10.1016/j.bbi.2012.11.012

Yan CG, Rincon-Cortes M, Rinecki C, Sarro E, Colcombe S, Guilfoyle DN, Yang Z, Gerum S, Biswal BB, Milham MP, Sullivan RM, Catellanos FX (2017). Aberrant development of intrinsic brain activity in a rat model of caregiver maltreatment of offspring. Transl Psychiatry 17: e1005. DOI: 10.1038/tp.2016.276

Yang EJ, Lin EW, Hensch TK (2012). Critical period for acoustic preference in mice. Proc Natl Acad Sci USA 109: 17213-17220. DOI: 10.1073/pnas.1200705109

Zimmermann KS, Richardson R, Baker KD (2019). Maturational changes in prefrontal amygdala circuits in adolescence: implications for understanding fear inhibition during a vulnerable period of development. Brain Sci 9(3): E65. DOI: 10.3390/brainsci9030065 